\title{
BMJ Open Knowledge of symptoms, time to presentation and barriers to medical help-seeking among Omani women diagnosed with breast cancer: a cross- sectional study
}

\author{
Mohammed Al-Azri (i) , ${ }^{1}$ Khalid Al-Baimani, ${ }^{2}$ Huda Al-Awaisi, ${ }^{3}$ Zahid Al-Mandhari, ${ }^{4}$ \\ Jasem Al-Khamayasi, ${ }^{5}$ Yaseen Al-Lawati, ${ }^{5}$ Sathiya Murthi Panchatcharam ${ }^{6}$
}

To cite: Al-Azri M, Al-Baimani K, Al-Awaisi $\mathrm{H}$, et al. Knowledge of symptoms, time to presentation and barriers to medical helpseeking among 0mani women diagnosed with breast cancer: a cross-sectional study. BMJ Open 2021;11:e043976. doi:10.1136/ bmjopen-2020-043976

- Prepublication history for this paper is available online. To view these files, please visit the journal online (http://dx.doi. org/10.1136/bmjopen-2020043976).

Received 19 August 2020 Revised 28 November 2020 Accepted 30 November 2020

Check for updates

(c) Author(s) (or their employer(s)) 2021. Re-use permitted under CC BY-NC. No commercial re-use. See rights and permissions. Published by BMJ.

For numbered affiliations see end of article.

Correspondence to Dr Mohammed Al-Azri; mhalazri@squ.edu.om

\section{ABSTRACT}

Objective To identify knowledge of breast cancer (BC) symptoms, time taken to consult a doctor and factors contributing to delays in medical help-seeking.

Design A cross-sectional study of Omani women diagnosed with BC.

Setting The two main teaching hospitals in Oman: Royal Hospital and Sultan Qaboos University Hospital.

Participants Adult Omani women recently diagnosed with BC. Tools The Breast Module of the Cancer Awareness Measure and the International Cancer Benchmarking Partnership questionnaire were used to collect data.

Results A total of 300 women with $\mathrm{BC}$ participated (response rate: $91.0 \%$ ). The mean age at diagnosis was $43.0 \pm 12.50$ years and $33.5 \%$ were diagnosed at stage III or IV. Although most women $(74.4 \%)$ recognised breast/armpit lumps to be a symptom of $\mathrm{BC}$, less than half identified other symptoms, including breast/armpit pain (44.0\%), changes in the position of the nipple (36.2\%), redness (31.7\%), fatigue (26.3\%), weight loss (23.4\%) and loss of appetite (20.8\%). While most $(91.6 \%)$ were aware that BC could be cured if detected early, only $66.4 \%$ sought medical help within a month of developing symptoms. Initial responses to symptoms included informing husbands (40.2\%) or family members $(36.5 \%)$. Barriers to seeking medical help included feeling scared (68.9\%) and worried about what the doctor might find (62.8\%). Highly educated women were more likely to recognise the following as $\mathrm{BC}$ symptoms: changes in nipple position (OR: $0.16,95 \% \mathrm{Cl}$ 0.03 to 0.81 ), breast pain (OR: $0.10,95 \% \mathrm{Cl} 0.01$ to 0.86 ) and unexplained weight loss (OR: $0.18,95 \% \mathrm{Cl} 0.04$ to 0.88 ) (all $\mathrm{p}<0.05$ ).

Conclusions Although many Omani women with $\mathrm{BC}$ were aware of the importance of early diagnosis, most demonstrated inadequate knowledge of symptoms, did not prioritise seeking medical help and reported emotional barriers to help-seeking. More educational measures are needed to improve symptom recognition and address help-seeking barriers to minimise delays in diagnosis.

\section{BACKGROUND}

Worldwide, breast cancer (BC) accounts for $10 \%$ of all cancers diagnosed annually and approximately $15 \%$ of all cancer deaths

\section{Strengths and limitations of this study}

- This is the first study conducted in Oman to explore time taken to seek medical help and barriers to seeking medical help among women diagnosed with breast cancer $(\mathrm{BC})$.

- Although women were aware of the importance of early detection of $\mathrm{BC}$ and that delays in seeking medical help could lead to complications, most presented at relatively advanced stages, with the cause for delay usually being due to the patients themselves.

- The initial response on first noticing possible BC symptoms was to inform husbands and family members rather than seeking medical help.

- The possibility of recall and response bias could not be ruled out due to the use of self-reported questionnaire measures for data collection.

- While the Arabic version of the final questionnaire was assessed for reliability, the validity of this measure was not determined.

among women. ${ }^{1}$ Despite efforts to improve the early detection of $\mathrm{BC}$, nearly one-third of women worldwide have either regional or distant metastasis at the time of diagnosis. ${ }^{2}$ In the Gulf Cooperation Council (GCC) region, $\mathrm{BC}$ is the most commonly diagnosed cancer among women, accounting for 13\%-35\% of all cancers; moreover, approximately half of patients with $\mathrm{BC}$ are under 50 years of age at the time of diagnosis, with a median age of 49-52 years compared with 63 years in Western countries. ${ }^{3}$ In addition, approximately $58.0 \%$ of women in GCC countries present with advanced stages of $\mathrm{BC}$ at diagnosis (45\% with regional metastasis and $12.8 \%$ with distant metastasis). ${ }^{4}$

Nonetheless, there is a high chance of a cure if BC is detected early and adequately treated; for example, women who begin 
treatment within 3-5 months of developing symptoms have significantly worse survival rates compared with those who seek medical help in $<3$ months. ${ }^{56}$ Delays in cancer diagnosis can occur at any time between the first symptom being noticed and the start of treatment. ${ }^{7}$ The most common cause of delay is usually because patients do not correctly identify cancer symptoms or act on them to seek medical help. ${ }^{89}$ Low awareness of BC symptoms, lack of access to care, unavailability or non-participation in BC screening, fatalism, negative perceptions of BC and cultural beliefs are all factors which contribute to delays in seeking medical help on the part of patients. ${ }^{28} 10-12$

The Pathways to Treatment model is a framework which defines the various temporal stages which occur between the onset of recognisable symptoms and the start of treatment and is often used to contextualise the various processes involved in symptom appraisal and help-seeking behaviours. ${ }^{13}$ The model is based on the notion that the process of general healthcare-seeking is complex and influenced by a mixture of physical, social and psychological factors. Key time points along the diagnostic pathway include the detection of initial bodily changes (symptoms), the perception of such changes as abnormal (symptom appraisal), the development of perceived reasons to consult with a doctor, the decision and action of consulting the doctor, and finally the diagnosis and start of the treatment. ${ }^{13}$

In Oman, BC is the most commonly diagnosed cancer and accounts for $12.79 \%$ of all cancers and $21.2 \%$ of cancers affecting women. ${ }^{14}$ Recently, the incidence of BC has almost doubled from 13.6 cases per 100000 women in 1996 to 26.9 in $2015 .{ }^{14}$ Like other GCC countries, the majority of women diagnosed with BC in Oman are younger (median age: 49 years) and present at advanced stages (ie, stages III and IV), with a low 5 -year survival rate $(63 \%) .{ }^{15}$ Several factors contribute to delays in cancer diagnosis in Oman, including the lack of a national screening programme, social stigma, the influence of family, spouses and friends in treatment decision-making, and the prevalence of traditional medicine and medical tourism. ${ }^{816-18}$ Identifying specific factors which contribute to delays in BC diagnosis is crucial to help improve patient outcomes. The aim of this study was therefore to identify knowledge of BC symptoms, time taken to seek medical help and barriers to medical help-seeking among Omani women diagnosed with BC.

\section{METHODS}

\section{Study setting}

This cross-sectional study was carried out between November 2018 and April 2019 at the National Oncology Centre of the Royal Hospital (RH) and the Oncology Unit of the Sultan Qaboos University Hospital (SQUH), both of which are located in Muscat, the capital city of Oman. These hospitals represent the two primary oncology centres in Oman and provide comprehensive treatment (including surgery, chemotherapy and radiotherapy) and palliative care to patients diagnosed with all types of cancer, including BC. ${ }^{19}$ The majority of patients diagnosed with $\mathrm{BC}$ at other regional hospitals of Oman are referred to either RH or SQUH for treatment.

\section{Sample size estimation and recruitment}

According to previous data from the National Cancer Registry from 1999 to 2015, the number of patients with BC in 2018 and 2019 was estimated to be 271 based on a linear prediction model. ${ }^{14}$ Thus, Omani women diagnosed with $\mathrm{BC}$ at RH or SQUH during the year prior to data collection were targeted for inclusion in the current study, as having been diagnosed more than a year previously could have resulted in recall bias.

A total of 330 adult Omani women aged $\geq 18$ years and diagnosed with $\mathrm{BC}$ within the preceding year at $\mathrm{RH}$ or SQUH were identified from the electronic hospital systems and invited to participate in the study. The names of the patients and the date of their next visit to outpatient oncology clinics and day care units or admission to wards were identified. Two different researchers over a period of 6 months were involved in the data collection process in order to increase the number of participants in the study. Also, women who did not respond were contacted again and the date of their next appointment recorded.

Patients were informed that participation in the study was optional and would not affect the medical care they received. Only women who agreed to participate were included in the study. Women who were in obvious distress or pain and those who were admitted due to complications such as febrile neutropaenia were excluded. All participants signed a consent form prior to taking part in the study.

\section{Tool used to measure BC symptom knowledge and barriers to seeking medical help}

The Breast Module of the Cancer Awareness Measure (Breast-CAM) was developed by the Cancer Research, King's College London and University College London in the UK and is a valid and reliable instrument for measuring BC awareness in women. ${ }^{20}{ }^{21}$ It has moderate to good test-retest reliability for most items, with a good discriminatory index of BC knowledge, and can be administered either face-to-face or via telephone interviews. ${ }^{20} 21$ The Breast-CAM was intended to be delivered to women in the community and includes different sections which independently measure and assess the following: knowledge of $\mathrm{BC}$ symptoms (ie, changes in the nipple, pain or lumps in the breast or armpit, redness, fatigue, unexplained weight loss and loss of appetite) and barriers to seeking medical help, including emotional (ie, being too embarrassed, scared or worried about what the doctor might find), practical (ie, being too busy to make time, having too many other things to worry about and anticipating difficulties explaining concerns to the doctor) and service-related barriers (ie, difficulties arranging transport or being worried about wasting the doctor's time) ${ }^{20}$ 


\section{Tool used to measure time taken to seek medical help}

The International Cancer Benchmarking Partnership (ICBP) was initiated by the Department of Health in the UK and was subsequently used as part of a collaborative research project to study international variations in cancer survival between jurisdictions in six countries, including Australia, Canada, Denmark, Norway, Sweden and the UK. ${ }^{7}$ The module seeks to measure the overall time interval between the first possible symptom of cancer and the start of treatment. ${ }^{7}$ This overall interval is then divided into subintervals depending on the factors responsible for the delay, including delays related to the patient's attitudes and help-seeking behaviours (ie, their initial response on first noticing symptoms and the duration of symptoms before contacting the doctor), the diagnostic process (ie, time elapsed to secure an appointment to see the doctor, number of medical visits before receiving a diagnosis, and time elapsed between being referred to hospital and getting an appointment with a specialist) and the treatment or management process (ie, time elapsed between first medical appointment and diagnosis, and between diagnosis and first receiving treatment). ${ }^{7}$ The ICBP questionnaire has been used in several international studies to investigate the root causes of delays in cancer diagnoses. ${ }^{22} 23$

For the purposes of the current study, the Breast-CAM and ICBP tools were combined into one questionnaire in order to assess knowledge of BC symptoms, time taken to consult a doctor and barriers to seeking medical help among Omani women. Sociodemographic variables in the modules were modified to be relevant to Omani society and the national healthcare system. Both the Breast-CAM and ICBP tools were translated from English to Arabic and then back-translated into English.

The combined questionnaire was completed by two researchers during face-to-face interviews conducted with the participants. In order to ensure the clarity and reliability of the questionnaire, a pilot study was conducted of the first 30 women enrolled in the study. Based on a standardised item analysis, the Cronbach's alpha $(\alpha)$ values of the Arabic versions of the Breast-CAM tool and ICBP questionnaire were 0.88 and 0.85 , respectively.

\section{Statistical analysis}

Data were analysed using SPSS V.22 software. Descriptive data were presented as numbers and percentages. $\chi^{2}$ test was used to determine the associations between sociodemographic characteristics and the responses of the participants. A binary logistic regression model was used to adjust for the effect of certain factors, with the findings presented as OR and $95 \%$ CI. A $p$ value of $<0.05$ was considered significant.

\section{Patient and public involvement}

Patients and/or the public were not involved in the design, or conduct, or reporting, or dissemination plans of this research.

\section{RESULTS}

\section{Characteristics of the participants}

A total of 300 women with BC participated in the study out of 333 eligible subjects, resulting in a response rate of $91.0 \%$. The mean age was $47.0 \pm 12.2$ years (median: 45.0 years, range: $24-84$ years). The majority were below the age of 50 years $(66.1 \%)$ and married $(76.2 \%)$. Over one-third were residents of Muscat (34.3\%) and had no formal education (35.2\%). Overall, 81 patients (27.1\%) reported having a family history of $\mathrm{BC}$, of which the majority $(76.3 \%)$ were first-degree or second-degree relatives. The mean age at BC diagnosis was $43.0 \pm 12.50$ years.

At the time of the interviews, the length of the time since diagnosis was less than 3 months in $15.5 \%$ of women. Moreover, $33.5 \%$ of women had been diagnosed at late stages (ie, stages III and IV). The women were receiving various treatment modalities at the time of the interviews, including chemotherapy, radiotherapy and hormonal therapy (table 1).

\section{Knowledge of BC symptoms and barriers to seeking medical help}

The majority of women were aware that BC could be cured if detected sufficiently early $(91.6 \%)$ and that delays in seeking medical treatment could adversely affect their health $(91.6 \%)$. Moreover, the majority were aware that missing or delaying an appointment to visit the doctor could cause delays in treatment $(90.2 \%)$ and that delays in diagnosis could lead to complications (89.0\%). On the other hand, less than half of the women $(43.8 \%)$ had been aware of $\mathrm{BC}$ prior to their diagnosis. Under onethird of the cohort thought that a BC diagnosis could lead to social stigma (24.2\%) and that society had an effect in delaying BC treatment (30.2\%) (figure 1).

The majority of women $(74.7 \%)$ were aware that lumps in the breast or armpit could be symptoms of BC. However, less than half were aware that pain in the breast or armpit $(44.0 \%)$, changes in the position of the nipple $(36.2 \%)$, redness of the skin of the breast $(31.7 \%)$, fatigue (26.3\%), unexplained weight loss $(23.4 \%)$ and loss of appetite $(20.8 \%)$ were possible BC symptoms (figure 2). The most commonly reported barriers to seeking medical help were fear $(68.9 \%)$, followed by anxiety over what the doctor might find $(62.8 \%)$, having too many other things to worry about (43.6\%), embarrassment (26.0\%), being too busy to make time to go to the doctor $(19.5 \%)$, difficulties arranging transport (13.7\%), difficulties explaining their symptoms to the doctor $(12.4 \%)$ and worry over wasting the doctor's time $(8.1 \%)$ (figure 3 ).

\section{Associations between sociodemographic characteristics and responses}

The binary logistic regression analysis indicated that women who had no formal education were less likely than those who were highly educated (ie, college and above) to recognise that the following were potential symptoms of BC: changes in the position of the nipple (OR 0.16 (95\% CI 0.03 to 0.81$), \mathrm{p}<0.05)$, pain in the breast or armpit 
Table 1 Sociodemographic and clinical characteristics as stated by the participants $(\mathrm{N}=300)$

\begin{tabular}{|c|c|c|}
\hline Variables & $\mathbf{n}$ & $\%$ \\
\hline \multicolumn{3}{|l|}{ Age (years) $(n=298)$} \\
\hline$\leq 40$ & 109 & 37 \\
\hline $41-50$ & 88 & 30 \\
\hline$>50$ & 101 & 34 \\
\hline \multicolumn{3}{|l|}{ Marital status ( $\mathrm{n}=298)$} \\
\hline Single & 21 & 7 \\
\hline Married & 227 & 76 \\
\hline Divorced & 11 & 3.7 \\
\hline Widowed & 39 & 13 \\
\hline \multicolumn{3}{|l|}{ Origin $(n=297)$} \\
\hline Muscat & 102 & 34 \\
\hline Ad Dhahirah & 33 & 11 \\
\hline Al Batinah & 60 & 20 \\
\hline Ad Dakhiliyah & 40 & 14 \\
\hline Al Wusta & 1 & 0.3 \\
\hline Ash Sharqiyah & 41 & 14 \\
\hline Dhofar & 5 & 1.7 \\
\hline Musandam & 2 & 0.7 \\
\hline Al Buraimi & 13 & 4.4 \\
\hline \multicolumn{3}{|l|}{ Educational level $(n=298)$} \\
\hline No formal education & 105 & 35 \\
\hline Primary and elementary & 37 & 12 \\
\hline High school & 93 & 31 \\
\hline College and above & 63 & 21 \\
\hline \multicolumn{3}{|l|}{ Employment status $(n=293)$} \\
\hline Employed & 97 & 33 \\
\hline Unemployed/housewife & 196 & 67 \\
\hline \multicolumn{3}{|c|}{ Monthly family income in OMR $(n=281)$} \\
\hline$\leq 500$ & 110 & 39 \\
\hline $501-1000$ & 99 & 35 \\
\hline$>1000$ & 72 & 26 \\
\hline
\end{tabular}

Family history of BC $(n=299)$

\begin{tabular}{lrr} 
Yes & 81 & 27 \\
\hline No & 218 & 73 \\
If yes, degree of relationship $(\mathrm{n}=80)$ & & \\
\hline First-degree & 29 & 36 \\
\hline Second-degree & 32 & 40 \\
\hline Third-degree & 19 & 24 \\
\hline Overall length of time since diagnosis (months) & $(\mathrm{n}=297)$ \\
\hline$<3$ & 46 & 16 \\
\hline $3-6$ & 165 & 56 \\
\hline $6-12$ & 86 & 29 \\
Stage of BC at diagnosis $(\mathrm{n}=299)$ & & \\
\hline Stage I & 62 & 21 \\
\hline
\end{tabular}

Continued

\begin{tabular}{lcc} 
Table 1 Continued & & \\
\hline Variables & $\mathbf{n}$ & $\%$ \\
\hline Stage II & 81 & 27 \\
Stage III & 55 & 18 \\
Stage IV & 45 & 15 \\
I don't know & 56 & 19 \\
Treatment modality at time of interview $(\mathrm{n}=261)$ & \\
Radiotherapy & 135 & 52 \\
Hormonal therapy & 94 & 36 \\
Targeted biological therapy & 37 & 14 \\
Chemotherapy & 202 & 77 \\
Surgery & 154 & 59 \\
I don't remember & 33 & 13 \\
\hline
\end{tabular}

$\mathrm{BC}$, breast cancer; OMR, Omani riyal.

(OR 0.10 (95\% CI 0.01 to 0.86 ), $\mathrm{p}<0.05$ ) and unexplained weight loss (OR 0.18 (95\% CI 0.04 to 0.88$), \mathrm{p}<0.05)$. On the other hand, women educated to the high school level were more likely than college-educated women to recognise that a lump in the breast or armpit (OR 7.28 (95\% CI 1.06 to 50.19$), \mathrm{p}<0.05$ ) and fatigue (OR 3.82 (95\% CI 1.08 to 13.58$), \mathrm{p}<0.05$ ) could be $\mathrm{BC}$ symptoms.

Employed women were more likely than unemployed women to recognise that fatigue could be a symptom of BC (OR 4.18 (95\% CI 1.34 to 13.05), $\mathrm{p}<0.05)$. In addition, women in the lowest income category were more likely than those in the highest category to recognise that pain in the breast or armpit (OR 4.14 (95\% CI 1.14 to 15.12), $\mathrm{p}<0.05)$ and redness (OR 3.58 (95\% CI 1.11 to 11.52), $\mathrm{p}<0.05$ ) could be BC symptoms (table 2 ).

Time taken to seek medical help

The initial response of most women on first noticing possible $\mathrm{BC}$ symptoms was to inform their husband $(40.2 \%)$, followed by informing other family members $(36.5 \%)$ and seeing a doctor at a government hospital $(8.4 \%)$, local health centre (LHC) $(8.1 \%)$ or private facility $(2.4 \%)$; however, few women reported travelling abroad $(2.0 \%)$, informing friends $(1.7 \%)$ or using traditional or herbal remedies $(0.7 \%)$. Of all respondents, less than half $(31.2 \%)$ decided to see a doctor within the first week of developing possible BC symptoms and $17.7 \%$ were able to get an appointment to see a doctor on the

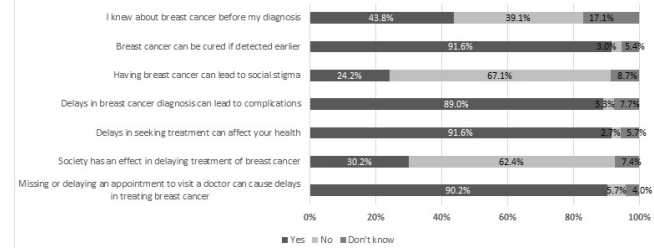

Figure 1 General knowledge of breast cancer and delays in diagnosis. 


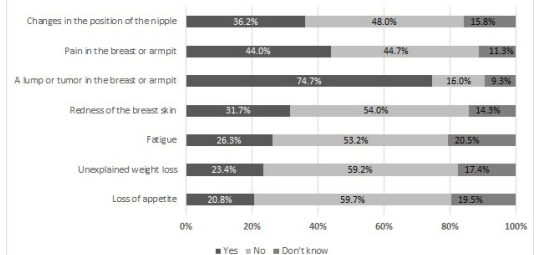

Figure 2 Knowledge of specific signs and symptoms of breast cancer.

same day or the next day following their decision to seek medical help.

The majority of women were diagnosed with $\mathrm{BC}$ after their first visit to an LHC $(67.7 \%)$ or to government hospitals $(30.1 \%)$. Moreover, many women were able to see specialists at government hospitals within less than 1 week of referral $(39.5 \%)$ and received confirmation of the diagnosis on the same day or the next day following their first appointment (10.4\%). Finally, many women $(29.9 \%)$ were able to receive their first treatment within the first week of their diagnosis (table 3 ).

Based on an indepth regression analysis, no significant associations were observed between sociodemographic variables and awareness of $\mathrm{BC}$ symptoms or help-seeking behaviours (ie, time taken for medical consultation, referral and treatment).

\section{DISCUSSION}

To our knowledge, this is the first study conducted in Oman to explore knowledge of BC symptoms, time taken to seek medical help and barriers to seeking medical help among women with BC. The mean age of the women diagnosed with $\mathrm{BC}$ in this study was 43 years; this is much lower than the average age reported in developed countries (mean age: 63 years) and slightly below that reported in other Arab countries (mean age: 49-52 years). ${ }^{3}$ A previous study conducted in Oman shared similar findings in which the mean age of women diagnosed with $\mathrm{BC}$ was 47 years, with one-third being under 40 years. ${ }^{15}$ The younger age of presentation of women with BC in Oman might be attributable to various factors, including genetic background, the adoption of more 'Westernised' lifestyles (including reduced levels of physical activity and higher rates of obesity), a decrease in breast feeding and the presence of potential carcinogens in the local environment. ${ }^{24}$

Although the vast majority of women in this study were aware of the importance of early detection of $\mathrm{BC}$

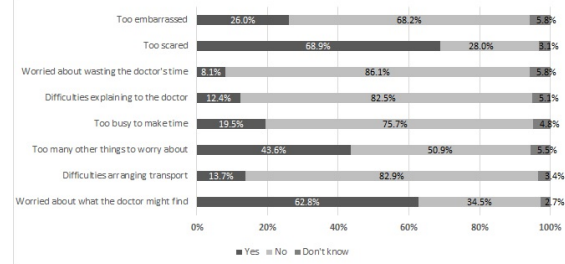

Figure 3 Barriers to medical help-seeking. and that delays in seeking medical help could lead to complications, many nevertheless presented at relatively advanced stages (ie, stage III or IV). Previous studies have reported similar findings. ${ }^{1525}$ Although a large proportion of women in this study were able to recognise that lumps in the breast or armpit were a possible symptom of $\mathrm{BC}$, the majority were not aware of other symptoms such as fatigue, unexplained weight loss or loss of appetite. Indeed, less than half of the women reported having been aware of or knowledgeable regarding BC prior to their own diagnosis. Researchers have recommended incorporating information regarding cancer risk factors and symptoms into the school curriculum so as to increase cancer knowledge in adulthood. ${ }^{26}$

Poor awareness of $\mathrm{BC}$ symptoms is a predominant reason for delayed presentation to a doctor, particularly if symptoms are atypical in nature. ${ }^{9}$ Most women with BC more commonly recognise obvious symptoms, such as lumps, compared with more ambiguous symptoms, such as tiredness, unexplained weight loss and reduced appetite; in fact, delays in presentation are more likely to occur in BC cases in which the symptoms do not include a breast lump. ${ }^{611}$ Furthermore, knowledge of BC symptoms is a prerequisite for prompt help-seeking behaviours, particularly if the symptom is perceived to be serious. ${ }^{27}$ Uneducated women in our study were less likely to recognise certain BC symptoms, such as changes in the position of the nipple, breast or armpit pain and unexplained weight loss. Similar findings have also been noted among Omani women with ovarian cancer, with more educated women being more likely to recognise specific symptoms compared with those who were less educated. ${ }^{28}$ Although more educated women in the current study were generally more likely to recognise BC symptoms compared with less educated women, the opposite was true for certain items. Specifically, women educated to the high school level were more likely than those with college degrees to understand that lumps in the breast or armpit or fatigue could be BC symptoms. Similarly, women in the low income group were more likely to understand that pain and redness could be associated with BC compared with those with high income. This contradicts results reported by a previous study. ${ }^{28}$ Reasons for these surprising findings are not clear and merit further investigation.

More than half of women in our study who sought medical help at LHCs or government hospitals were diagnosed with $\mathrm{BC}$ after their first or second visit, indicating that the cause for any delays in diagnosis was likely due to the patients themselves. Other researchers have highlighted that not seeking early medical help is a predictor of delayed diagnosis. ${ }^{8}{ }^{29}$ Furthermore, the majority of women who were seen at LHCs in the present study were subsequently seen by specialists within 2 weeks of referral, with the $\mathrm{BC}$ diagnosis confirmed within another 2 weeks. Once again, this indicates that factors related to the local health system do not seem to play a major role in delaying BC diagnoses in Oman. Referral policies covering specific aspects of patient care are well established to oversee 


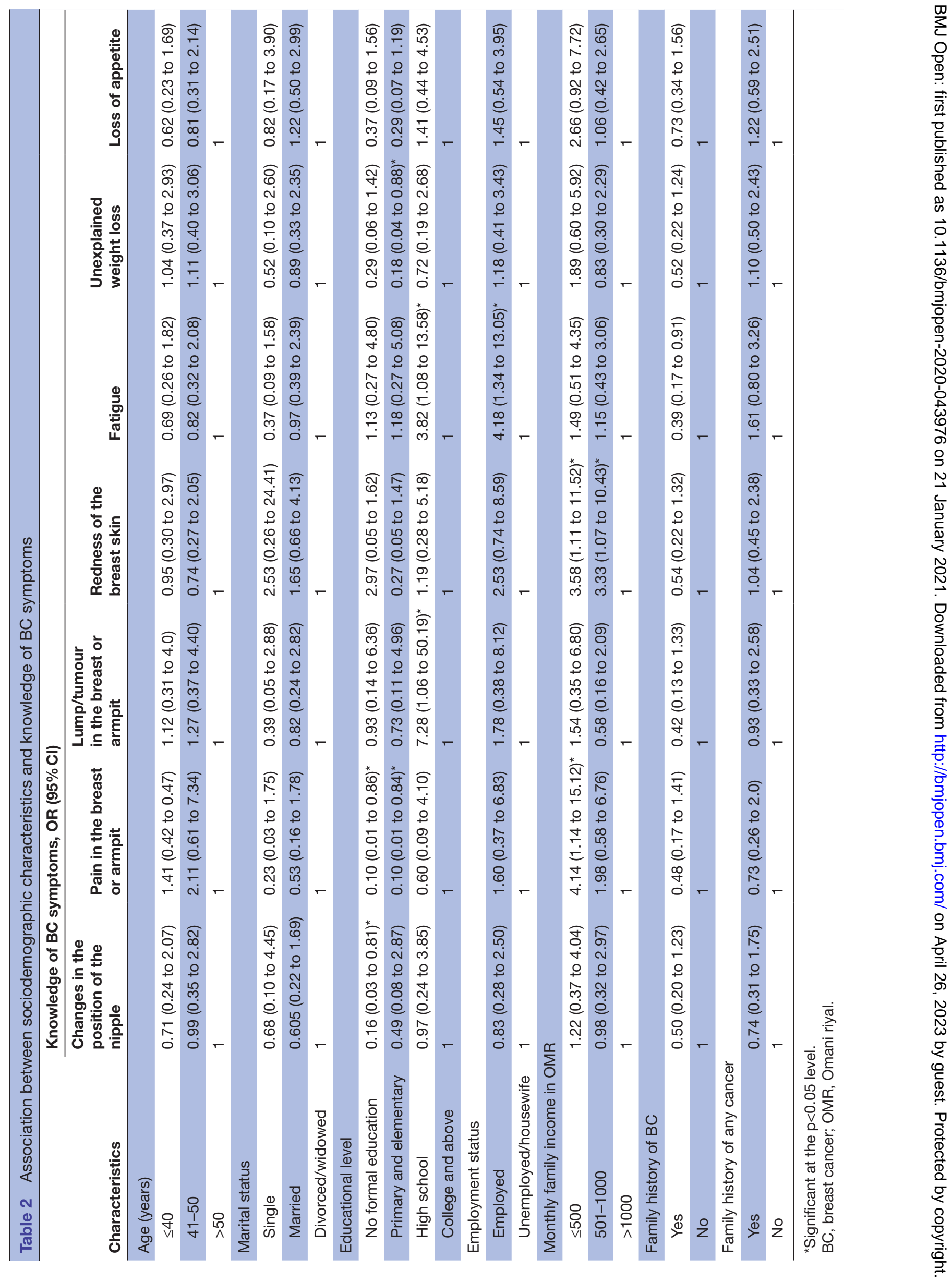


Table 3 Time taken for medical consultation, referral and treatment of $B C$ as stated by the participants $(\mathrm{N}=300)$

\begin{tabular}{lrc}
\hline Variables & $\mathbf{n}$ & $\%$ \\
\hline $\begin{array}{l}\text { Initial response on first noticing possible BC } \\
(\mathrm{n}=296)\end{array}$ & 119 & 40 \\
\hline Informing husband & 108 & 37 \\
\hline Informing family members & 25 & 8.4 \\
\hline Seeing a doctor in a government hospital & 24 & 8.1 \\
Seeing a doctor in a local health centre & 24 & 7.4 \\
Seeing a doctor in a private sector facility & 7 & 2.4 \\
Travelling abroad & 6 & 2 \\
\hline Informing friends & 5 & 1.7 \\
\hline Using traditional/herbal medicine & 2 & 0.7
\end{tabular}

Approximate duration of symptom(s) before contacting a doctor $(\mathrm{n}=298)$

\begin{tabular}{|lcc|}
\hline$<1$ week & 93 & 31 \\
\hline $1-2$ weeks & 46 & 15 \\
\hline-4 weeks & 59 & 20 \\
\hline-7 weeks & 24 & 8.1 \\
\hline-5 months & 38 & 13 \\
\hline-12 months & 18 & 6 \\
\hline 12 months & 20 & 6.7 \\
\hline
\end{tabular}

Length of time between contacting a doctor and getting an appointment $(n=294)$

\begin{tabular}{|c|c|c|}
\hline Same/next day & 52 & 18 \\
\hline$<1$ week & 78 & 27 \\
\hline $1-2$ weeks & 61 & 21 \\
\hline 3-4 weeks & 54 & 18 \\
\hline $1-2$ months & 35 & 12 \\
\hline$>3$ months & 14 & 4.8 \\
\hline \multicolumn{3}{|c|}{ Number of medical visits before being diagnosed } \\
\hline \multicolumn{3}{|c|}{ At local health centres $(n=155)$} \\
\hline 1 & 105 & 68 \\
\hline 2 & 27 & 17 \\
\hline 3 & 23 & 15 \\
\hline
\end{tabular}

At government hospitals $(\mathrm{n}=209)$

$\begin{array}{lll}1 & 63 & 30 \\ 2 & 44 & 21 \\ 3 & 47 & 23 \\ \geq 4 & 55 & 26\end{array}$

Length of time between being referred to hospital and getting an appointment with a specialist $(\mathrm{n}=296)$

\begin{tabular}{lrc}
$<1$ week & 117 & 40 \\
$1-2$ weeks & 94 & 32 \\
$3-4$ weeks & 58 & 20 \\
$5-7$ weeks & 12 & 4.1 \\
2-5 months & 8 & 2.7 \\
$6-12$ months & 3 & 1 \\
\hline
\end{tabular}

Continued
Table 3 Continued

\begin{tabular}{|c|c|c|}
\hline Variables & $\mathbf{n}$ & $\%$ \\
\hline$>12$ months & 4 & 1.4 \\
\hline \multicolumn{3}{|c|}{$\begin{array}{l}\text { Approximate length of time between first medical } \\
\text { appointment and diagnosis }(n=297)\end{array}$} \\
\hline Same/next day & 31 & 10 \\
\hline$<1$ week & 72 & 24 \\
\hline 1-2 weeks & 92 & 31 \\
\hline 3-4 weeks & 53 & 18 \\
\hline $1-2$ months & 30 & 10 \\
\hline $3-6$ months & 10 & 3.4 \\
\hline$>6$ months & 9 & 3 \\
\hline \multicolumn{3}{|c|}{$\begin{array}{l}\text { Length of time between diagnosis and first receiving } \\
\text { treatment }(n=294)\end{array}$} \\
\hline$<1$ week & 88 & 30 \\
\hline $1-2$ weeks & 84 & 29 \\
\hline 3-4 weeks & 58 & 20 \\
\hline $1-2$ months & 46 & 16 \\
\hline$>3$ months & 18 & 6.1 \\
\hline
\end{tabular}

$\mathrm{BC}$, breast cancer.

the transfer of patients from one healthcare setting to another for management. ${ }^{30}$ Nonetheless, patients with cancer in Oman, much like those in neighbouring GCC countries, often choose to seek medical help abroad (ie, in countries like Thailand or India); this trend can cause delays in diagnosis, with many patients returning home with additional complications. ${ }^{16}$

For the majority of women in the current study, their initial response on first noticing possible BC symptoms was to inform their husbands and family members. Becoming aware of possible symptoms of a life-threatening disease is often associated with feelings of emotional distress, anxiety and depression; hence, sharing this information with close family members might offer some emotional relief and support. ${ }^{31}{ }^{32}$ Indeed, most women in our study prioritised sharing their symptoms with husbands or family members over consulting a doctor. This finding might be related to prevailing sociocultural attitudes which are based on a strong sense of moral responsibility and familial obligation, particularly when it comes to illness. ${ }^{18}$ Furthermore, Omani women diagnosed with BC often rely on their families for emotional, physical and financial support, which also plays a role in treatment decision-making. ${ }^{17} 18$ However, the involvement of family members in medical decisions and treatment options can sometimes delay diagnoses, particularly if these individuals encourage patients to seek medical treatment abroad or pursue alternative or traditional remedies. ${ }^{83}$

Although more than half of the women in our study sought medical help within 1 month of developing BC symptoms, many nevertheless presented at an advanced stage by the time they were diagnosed. Various psychosocial and cultural 
beliefs have been attributed to the delayed presentation of BC cases. ${ }^{162931}$ A previous study from Oman showed that women with BC experienced severe psychosocial distress, including fear of death, social isolation, anxiety regarding the side effects of treatment and fear that the cancer might spread or interfere with their daily lives. ${ }^{16}$ Women who express explicit fears about the consequences of diagnosis and treatment are more reluctant to seek medical help, resulting in a higher chance of delays in diagnosis. ${ }^{11}$

Similarly, many women in our study reported emotional barriers that might contribute to delays in consulting a doctor, such as being scared, embarrassed or worried about what the doctor might find. Symptom appraisal and perception of their severity are predictors of decisions to seek medical help. ${ }^{29}$ Indeed, it is difficult to assess delays in BC presentation, diagnosis and treatment objectively due to variations in how people perceive symptoms and define time intervals. ${ }^{34}$ Although there is growing interest in measuring cancer diagnostic time intervals and examining their effect on outcomes, the pathway from symptoms to diagnosis is a complex process as outlined in the Pathways to Treatment framework. ${ }^{13}$

The decision to consult a doctor and seek medical help often relies on a patient's subjective definition of the 'main' symptoms of cancer, which in itself is often influenced by their pre-existing knowledge and perceptions of symptom severity. ${ }^{35}$ The presence of chronic diseases or psychological symptoms may also further influence interpretation of these symptoms. ${ }^{13}$ Furthermore, international variations in the investigation and referral of patients with cancer to secondary care for suspected cancer symptoms can play a critical role in diagnostic delays and cancer outcomes; for instance, countries in which healthcare professionals demonstrate a greater readiness to refer or investigate patients with possible cancer symptoms have demonstrated high rates of cancer survival. ${ }^{36}$

This study has certain limitations. First, many patients in Oman often choose to access healthcare in non-integrated settings, for instance, by attending a mixture of government facilities, private facilities and facilities abroad. Thus, it was difficult in some cases to track the time taken throughout the diagnostic pathway using the three usual component intervals of delay (ie, patient, primary care and secondary care delays). Apart from self-reported information from the patients, there were no other methods available to measure delays in the absence of electronic or written tracking data.

Second, while we recruited Omani women diagnosed with $\mathrm{BC}$ within the previous year to satisfy the sample size requirements, the possibility of recall bias cannot be ruled out. Third, although the Arabic version of the combined questionnaire (which incorporated both the Breast-CAM and ICBP tools) was tested for reliability and demonstrated a satisfactory Cronbach's alpha $(\alpha)$ coefficient, we could not guarantee its validity, which was beyond the scope of this research. Fourth, we provided women with a predetermined list of BC symptoms in the Breast-CAM module instead of asking them to demonstrate their own knowledge of such symptoms; this may have obscured our understanding of how knowledge influenced help-seeking behaviours. Finally, we used the Breast-CAM section to measure knowledge of BC symptoms and barriers to seeking medical help among patients who had already been diagnosed with $\mathrm{BC}$; as this tool was originally designed to be delivered to a community sample, we could not rule out potential bias in that the participants might have more knowledge of BC symptoms compared with other Omani women.

\section{CONCLUSION}

Omani women with BC demonstrated low levels of knowledge of BC symptoms and experienced several emotional barriers to seeking medical help; moreover, many were diagnosed at advanced stages. Despite national efforts to increase BC awareness, further educational initiatives are needed. Healthcare professionals should visit schools to raise awareness of BC symptoms and promote early help-seeking behaviours among female students in different regions of Oman. Employing both social and traditional media campaigns in LHCs and hospitals might also help to increase BC knowledge. Finally, healthcare professionals should make more efforts to build a trusting and cooperative relationship with female patients in order to help address emotional barriers to medical help-seeking, thereby encouraging them to disclose potential symptoms and thus reducing delays in diagnosis.

\section{Author affiliations}

${ }^{1}$ Family Medicine and Public Health, Sultan Qaboos University, Muscat, Oman ${ }^{2}$ Oncology Unit, Department of Medicine, Sultan Qaboos University, Muscat, Oman ${ }^{3}$ Nursing Directorate, Sultan Qaboos University Hospital, Sultan Qaboos University, Muscat, Oman

${ }^{4}$ Department of Oncology, The Royal Hospital, Muscat, Oman ${ }^{5}$ College of Medicine and Health Sciences, Sultan Qaboos University, Muscat, Oman ${ }^{6}$ Research Section, Medical Simulation and Skills Development Centre, Oman Medical Speciality Board, Muscat, Oman

\section{Twitter Mohammed Al-Azri @DrAlazri}

Acknowledgements The authors are grateful to the participating patients and to the authorities at RH and SQUH for allowing this study to take place. They are also grateful to the College of Medicine and Health Sciences at Sultan Qaboos University for funding the study.

Contributors MA-A, KA-B, HA-A, ZA-M, JA-K and YA-L conceived of the study and contributed to its design and implementation. JA-K and YA-L collected data. SMP performed the statistical analysis. MA-A drafted the manuscript. All authors read and approved the final version of the manuscript.

Funding This study was funded by an internal grant from the College of Medicine and Health Sciences, Sultan Qaboos University (\#IG/MED/FMC0/19/01).

Competing interests None declared.

Patient consent for publication Not required.

Ethics approval The study received ethical approval from the Medical Research and Ethics Committee of the College of Medicine and Health Sciences, Sultan Qaboos University (MREC \#1809), as well as the Scientific Research Committee of the Royal Hospital (SRC \#87/2018).

Provenance and peer review Not commissioned; externally peer reviewed.

Data availability statement The datasets used and/or analysed during this study are available from the corresponding author upon reasonable request.

Open access This is an open access article distributed in accordance with the Creative Commons Attribution Non Commercial (CC BY-NC 4.0) license, which permits others to distribute, remix, adapt, build upon this work non-commercially, and license their derivative works on different terms, provided the original work is properly cited, appropriate credit is given, any changes made indicated, and the use is non-commercial. See: http://creativecommons.org/licenses/by-nc/4.0/. 
ORCID iD

Mohammed Al-Azri http://orcid.org/0000-0002-6136-4081

\section{REFERENCES}

1 World Health Organization. Cancer: breast cancer. Available: https:// www.who.int/cancer/prevention/diagnosis-screening/breast-cancer/ en/ [Accessed Jul 2020].

2 Facione NC, Miaskowski C, Dodd MJ, et al. The self-reported likelihood of patient delay in breast cancer: new thoughts for early detection. Prev Med 2002;34:397-407.

3 Donnelly TT, Khater A-HA, Al-Bader SB, et al. Arab women's breast cancer screening practices: a literature review. Asian Pac J Cancer Prev 2013;14:4519-28.

4 El Saghir NS, Khalil MK, Eid T, et al. Trends in epidemiology and management of breast cancer in developing Arab countries: a literature and registry analysis. Int J Surg 2007;5:225-33.

5 Harford JB. Breast-cancer early detection in low-income and middleincome countries: do what you can versus one size fits all. Lancet Oncol 2011;12:306-12.

6 Richards MA, Westcombe AM, Love SB, et al. Influence of delay on survival in patients with breast cancer: a systematic review. Lancet 1999;353:1119-26.

7 Butler J, Foot C, Bomb M, et al. The International cancer benchmarking partnership: an international collaboration to inform cancer policy in Australia, Canada, Denmark, Norway, Sweden and the United Kingdom. Health Policy 2013;112:148-55.

8 Al-Azri MH. Delay in cancer diagnosis: causes and possible solutions. Oman Med J 2016;31:325-6.

9 Macleod U, Mitchell ED, Burgess C, et al. Risk factors for delayed presentation and referral of symptomatic cancer: evidence for common cancers. Br J Cancer 2009;101:S92-101.

10 Hisham AN, Yip C-H. Overview of breast cancer in Malaysian women: a problem with late diagnosis. Asian J Surg 2004;27:130-3.

11 Gorin SS, Heck JE, Cheng B, et al. Delays in breast cancer diagnosis and treatment by racial/ethnic group. Arch Intern Med 2006;166:2244-52.

12 Aziz NM, Rowland JH. Cancer survivorship research among ethnic minority and medically underserved groups. Oncol Nurs Forum 2002;29:789-801.

13 Scott SE, Walter FM, Webster A, et al. The model of pathways to treatment: conceptualization and integration with existing theory. $\mathrm{Br} \mathrm{J}$ Health Psychol 2013;18:45-65.

14 Al-Lawati JA, Al-Zakwani I, Fadhil I, et al. Cancer incidence in Oman (1996-2015). Oman Med J 2019;34:271-3.

15 Kumar S, Burney IA, Al-Ajmi A, et al. Changing trends of breast cancer survival in Sultanate of Oman. J Oncol 2011;2011:1-7.

16 Al-Azri M, Al-Awisi H, Al-Rasbi S, et al. Psychosocial impact of breast cancer diagnosis among Omani women. Oman Med J 2014;29:437-44.

17 Al-Bahri A, Al-Moundhri M, Al-Mandhari Z, et al. The role of patients' families in treatment decision-making among adult cancer patients in the Sultanate of Oman. Eur J Cancer Care 2018;27:e12845.

18 Al-Bahri A, Al-Moundhri M, Al-Mandhari Z, et al. Role of the family in treatment decision-making process for Omani women diagnosed with breast cancer. Patient Educ Couns 2019;102:352-9.

19 Burney IA, Al Moundhri MS, Rizvi AJ, et al. Outcome as a measure of quality of care in oncology: experience at sultan qaboos university Hospital, Oman. Sultan Qaboos Univ Med J 2008;8:27-36.
20 Cancer Research UK. Breast module of the cancer awareness measure (Breast-CAM) toolkit. Available: https://www. cancerresearchuk.org/sites/default/files/health_professional_breast_ cam_toolkit_09.02.11.pdf [Accessed Jul 2020].

21 Linsell L, Forbes LJL, Burgess C, et al. Validation of a measurement tool to assess awareness of breast cancer. Eur $J$ Cancer 2010;46:1374-81.

22 Forbes LJL, Simon AE, Warburton F, et al. Differences in cancer awareness and beliefs between Australia, Canada, Denmark, Norway, Sweden and the UK (the International cancer benchmarking partnership): do they contribute to differences in cancer survival? $\mathrm{Br}$ $J$ Cancer 2013;108:292-300.

23 Rose PW, Hamilton W, Aldersey K, et al. Development of a survey instrument to investigate the primary care factors related to differences in cancer diagnosis between international jurisdictions. BMC Fam Pract 2014;15:122.

24 Kim Y, Yoo K-Y, Goodman MT. Differences in incidence, mortality and survival of breast cancer by regions and countries in Asia and contributing factors. Asian Pac J Cancer Prev 2015;16:2857-70.

25 Al-Azri M, Al-Rubaie K, Al-Ghafri S, et al. Barriers and attitudes toward breast cancer screening among Omani women. Asian Pac J Cancer Prev 2020;21:1339-47.

26 Karayurt O, Ozmen D, Cetinkaya AC. Awareness of breast cancer risk factors and practice of breast self examination among high school students in Turkey. BMC Public Health 2008;8:359.

27 Quaife SL, Forbes LJL, Ramirez AJ, et al. Recognition of cancer warning signs and anticipated delay in help-seeking in a population sample of adults in the UK. Br J Cancer 2014;110:12-18.

28 Al-Azri M, Al-Saidi M, AL-Mutair E, et al. Awareness of risk factors, symptoms and time to seek medical help of ovarian cancer amongst Omani women attending teaching hospital in Muscat Governorate, Oman. Asian Pac J Cancer Prev 2018;19:1833-43.

29 Bish A, Ramirez A, Burgess C, et al. Understanding why women delay in seeking help for breast cancer symptoms. J Psychosom Res 2005;58:321-6.

30 Ministry of Health, Oman. Ministry of health directorate general of private health establishments referral policy. Available: https:// www.moh.gov.om/documents/10181/667459/Refferal+Policy.pdf/ 2705a237-9a47-428d-91e3-5a1a08baaa07 [Accessed Jul 2020].

31 Al-Azri MH, Al-Awisi $\mathrm{H}, \mathrm{Al}-\mathrm{Rasbi} \mathrm{S}$, et al. Coping with a diagnosis of breast cancer among Omani women. J Health Psychol 2014;19:836-46.

32 Al-Azri M, Al-Awisi H, Al-Moundhri M. Coping with a diagnosis of breast cancer-literature review and implications for developing countries. Breast J 2009;15:615-22.

33 Al-Lawati T, Mehdi I, AlBahrani B, et al. Does alternative and traditional wasam (local cautery) therapy facilitate an early and more extensive locoregional metastasis of breast cancer? Gulf J Oncolog 2016;1:37-42.

34 Andersen RS, Vedsted P, Olesen F, et al. Patient delay in cancer studies: a discussion of methods and measures. BMC Health Serv Res 2009;9:189.

35 Coxon D, Campbell C, Walter FM, et al. The Aarhus statement on cancer diagnostic research: turning recommendations into new survey instruments. BMC Health Serv Res 2018;18:677.

36 Rose PW, Rubin G, Perera-Salazar R, et al. Explaining variation in cancer survival between 11 jurisdictions in the International cancer benchmarking partnership: a primary care vignette survey. BMJ Open 2015;5:e007212. 